\title{
SARS: A tale of two epidemics
}

\author{
John M Conly $\mathrm{MD}^{1}$, B Lynn Johnston $\mathrm{MD}^{2}$
}

$I^{\mathrm{n}}$

In November 2002, cases of a life-threatening respiratory disease of 1 unknown cause were reported from Guangdong Province, China, followed in early 2003 by reports from Vietnam and Hong Kong. The illness was designated as severe acute respiratory syndrome (SARS) in late February 2003 (1-3). In Vietnam the outbreak began with a single initial patient who was hospitalized for treatment of a severe, acute respiratory syndrome of unknown origin (4). The patient felt unwell during his journey and fell ill shortly after arriving in Hanoi from Shanghai and Hong Kong. By March 10, 2003, following the patient's admission to a Hanoi hospital, approximately 22 hospital staff became ill with similar symptoms. By March 12, 2003 similar outbreaks had been reported among health care workers in Hong Kong. Recognizing the transmission of the illness to health care workers, the World Health Organization (WHO) issued a rare global health alert on March 12, 2003 (4). On March 14, 2003 the WHO received notification from Health Canada of four cases of a severe atypical pneumonia with an associated death in a single family in Toronto. Reports of probable SARS cases followed in Singapore, the Amoy Gardens apartment complex in Hong Kong, Taiwan, the United States and several European countries. As of April 28, 2003 a cumulative total of 5050 probable SARS cases with 321 deaths have been reported to the WHO from 26 countries (5). During this time the WHO has coordinated an international response unprecedented in modern times. The response has been aided significantly by the use of real-time communication and information exchange, much of it over the Internet using email and secure websites (6). The emergence of SARS in Canada has presented significant challenges, related not only to the epidemic of the disease itself but also to the epidemic of misconceptions and fear, which can present an even greater challenge. Given the recent unfolding of the SARS epidemic in Canada, it is considered timely to address the salient features of the disease and its potential repercussions. Are there lessons to be learned to better prepare us for the next new epidemic and pandemic influenza?

Several papers from investigators in Hong Kong and Canada have described the clinical, laboratory and radiological features of the disease (7-9). In the outbreak described by Lee et al (9), there were 138 cases of SARS, of which 69 were health care workers. The most common symptoms were fever of more than $38^{\circ} \mathrm{C}$ (displayed in $100 \%$ of patients), chills, rigors, or both $(73.2 \%$ of patients), myalgia (60.9\% of patients), cough $(57.3 \%$ of patients) headache (55.8\% of patients) and dizziness ( $42.8 \%$ of patients). Other symptoms that occurred less commonly included sore throat, coryza, nausea and vomiting, dyspnea, sputum production and diarrhea. Major examination findings included fever and crepitations at the lung bases. Leukopenia was present in about one-third of patients but absolute lymphopenia and thrombocytopenia were present in over two thirds and almost half of all patients, respectively. Other laboratory abnormalities included elevation of lactate dehydrogenase in $71 \%$ of patients, creatine kinase in $32 \%$, and serum alanine aminotransferase in $23 \%$. Electrolyte abnormalities were noted in some patients. Radiological abnormalities were present in $80 \%$ to $100 \%$ of the patients at presentation $(8,9)$, with initial findings of peripheral air space consolidation of a focal or multifocal nature that progressed after a week. In patients who deteriorated, progressive bilateral infiltrates were noted. Univariate analysis in one study (8) revealed that advanced age, presence of underlying illness, impaired liver function tests and late initiation of treatment were significantly associated with severe disease requiring intensive care and ventilatory support. Multivariate analysis in another study (9) with a larger number of patients revealed that advanced age (odds ratio of 1.8 for every 10 years), high lactate dehydrogenase and elevated absolute neutrophil count on presentation were associated with an adverse outcome. Another study (10) has suggested that chronic hepatitis B virus infection is also associated with a poor outcome. Major comorbidities were present in the majority of patients who have died (7-9). It is noteworthy that few reports of severe disease in children have emerged, despite significant exposure on a worldwide basis. One study (7) detailed exposure of three children (aged five months, nine years and 17 years) to an index case, all of whom had fever and/or respiratory symptoms but no evidence of pulmonary infiltrates on radiological examination. None of the children were reported as being hospitalized.

The epidemiological features of the disease suggest that it is transmissible from person-to-person through direct contact, large droplet contact, and through indirect contact from fomites and unwashed hands. The mean and median incubation periods are five and six days, respectively $(8,9)$. The maximum incubation period appears to be 10 days (11). The virus is present in the respiratory secretions of infected patients and has also been found in the urine and feces (7-9). Recent unpublished data (12) has demonstrated that the virus is stable in feces and urine at room temperature for at least one to two days. The virus is also more stable (up to four days) in stool from diarrhea patients (which has a higher $\mathrm{pH}$ ) than in normal stool, where it could only be found for up to six hours. These findings have raised the possibility of fecal-oral spread in some situations, a hypothesis yet to be confirmed.

In the search for an etiological agent, specimens from clinical cases of SARS were tested for a broad range of bacterial, viral, chlamydial and rickettsial agents. Initial laboratory testing focused

${ }^{1}$ Departments of Pathology and Laboratory Medicine, Medicine, and Microbiology and Infectious Diseases, University of Calgary, Calgary, Alberta;

${ }^{2}$ Queen Elizabeth II Health Sciences Centre and Dalhousie University, Halifax, Nova Scotia

Correspondence: Dr John Conly, Departments of Pathology and Laboratory Medicine, Medicine, and Microbiology and Infectious Diseases, Room 930, 9th Floor, North Tower, 1403 29th Street Northwest, Calgary, Alberta T2N 2T9. Telephone 403-944-8222,

fax 403-944-1095, e-mail jconly@ucalgary.ca and Dr Lynn Johnston, Department of Medicine, Room 5014 ACC, Queen Elizabeth II Health Sciences Centre, 1278 Tower Road, Halifax, Nova Scotia B3H 2Y9. Telephone 902-473-5553, fax 902-473-7394, e-mail ljohnsto@dal.ca 
on known pathogens which might affect the lower respiratory tract, and a combination of classical and molecular techniques were used. Multiple cell lines were inoculated and a novel coronavirus was isolated from several patients in several different countries who met the case definition of SARS $(13,14)$. Cytopathological features were noted on Vero E6 cells inoculated with respiratory specimens, and electron microscopic studies of the supernatant from these cell lines revealed characteristic features of a coronavirus (14). In addition, electron microscopy revealed the presence of a virus with characteristics of a coronavirus in some patient specimens. Consensus primers, designed to amplify a fragment of the polymerase gene of the coronavirus by reverse-transcription polymerase chain reaction, were used to obtain a sequence that identified the isolate as a unique and novel coronavirus that was only distantly related to other known coronaviruses (14). When compared to other human and animal coronaviruses, the nucleotide and amino acid sequence from a specific segment of the polymerase gene had similarity scores of 0.56 to 0.63 and from 0.57 to 0.74 respectively. Serological assays made with the newly identified coronavirus and using indirect fluoroscopy and enzyme-linked immunosorbence have shown a response specific to the virus. Ksiazek et al (14) proposed the name "Urbani SARS-associated virus" in commemoration of Dr Carlos Urbani, a physician whose work contributed significantly to the recognition of SARS and who died of this infection.

Pathological examination of lung tissue obtained at postmortem examinations revealed diffuse alveolar damage of various degrees of severity. The major changes included interstitial mononuclear infiltrates, desquamation of pneumocytes in alveolar spaces and hyaline membrane formation (14). Other findings included focal hemorrhage, necrotic debris in small airways and intra-alveolar multinucleated syncytial cells. Multiple techniques used to examine the lung tissue from the limited samples did not reveal evidence of the coronavirus.

The failure to date to detect antibodies in specimens from nonSARS patients suggests that the virus is new and has not previously circulated among the human population. It has been suggested that the virus originated in animals and somehow mutated in a manner that allowed it to infect and cause severe illness in humans and to be transmitted from person-to-person (14). Only one known coronavirus, which has been recently identified in respiratory infections in swine from China, has been able to replicate in Vero cells (14).

The extensive pulmonary infiltrates and tissue damage noted in the postmortem lung specimens suggest that cytokines or other factors induced by the viral infection may be responsible for the severe lung disease, rather than the virus itself. The presence of high fever, leucopenia, thrombocytopenia, altered liver function, and evolution into the adult respiratory distress syndrome suggest a severe systemic inflammatory response syndrome induced by this virus (8). It has been speculated that the severity of the response is similar to severe human disease associated with avian influenza virus $\mathrm{H} 5 \mathrm{~N} 1$, another virus that has crossed from the animal into the human population. There are many similarities with this disease including the demonstrated high cytokine response associated with avian influenza. Treatment with corticosteroids may immunomodulate the response and has been used as part of a treatment protocol in Hong Kong $(8,9)$ along with the antiviral ribavirin $(8,10)$. The benefit of ribavirin is not based on solid evidence and with no demonstrable in vitro activity, the lack of benefit in Canadian cases, and a high incidence of side effects, it has been removed as a special access drug by Health Canada for this indication (15).

As of April 28, 2003, Health Canada had received reports of 344 probable or suspect cases of SARS, including 20 deaths (16).
Transmission has occurred in household contacts, hospitals and, to a lesser degree, in community settings. All but 73 suspect and four probable cases have been reported from Ontario, specifically from Toronto. The response to SARS in Toronto has been nothing less than dramatic and has gripped the province, and indeed the nation, for several weeks. Ontario declared a health emergency to deal with SARS and has used very aggressive measures in its efforts to control the disease. The response to SARS in Toronto has used a number of strategies including: complete hospital closures; severe curtailing of hospital services (ie, emergency admissions only, no elective surgery, no hospital based diagnostic imaging procedures) in all hospitals in the Greater Toronto and Simcoe areas; massive screening of all individuals entering the hospital; restriction of access to health care facilities; positioning of security guards at entrance sites; restriction of visitors and volunteers; mandatory use of N95 masks in intensive care units, emergency rooms and wards with SARS patients; masking in settings, such as administrative offices, remote from actual disease; screening of health care workers attending community care centers; and widespread quarantine of casual contacts of SARS patients (17). It has been estimated that as many as 10,000 people were in quarantine at one time or another. In addition, several of the measures were extended to all hospitals in Ontario, regardless of whether they had SARS patients (18).

The use of these measures, and the declarations of the media and of some physicians to use even more aggressive measures (19, 20), sent a message that the city was in a complete "crisis situation". The constant media play, along with public statements from certain microbiologists and infection control experts that the SARS epidemic was worse than the 1918 influenza pandemic, and that North America was facing a crisis unprecedented since the emergence of AIDS, did little to help the situation created a heightened sense of anxiety and loss of control out of proportion to what was actually happening in the community. The messages conveyed did little to provide leadership or to instill a sense of calm and balance to the public of Ontario and the world at large.

At least one respected medical and public health expert has made a plea for "prudence, not panic", suggesting that poor communication, excessive precautions and failure to meet unrealistic goals fuelled public fears (21). He has also suggested that the hysteria of Toronto health officials created a sense of crisis that may have tipped the balance in favour of the WHO travel advisory against Toronto (22). Although these points may be arguable, there is no question that a secondary epidemic gripped Ontario, the epidemic of public fear of SARS. The costs may be enormous, not only to the reputation of Toronto as a city but to Canada as a whole. The Conference Board of Canada has predicted a $\$ 1$ billion loss to the economy of Toronto and a $\$ 1.5$ billion loss to the economy of Canada (23). The suspension of hospital services for close to a month in the Greater Toronto Area, the quarantining of over 10,000 people who were casual contacts of SARS patients and the collateral damage to patients barred from receiving care during this time have yet to be factored into the overall picture that is emerging. One expert has openly questioned the usefulness of this approach and the resulting high economic and human costs (24). Nonetheless, it may be acknowledged that it can be difficult to maintain objectivity in the middle of an outbreak with a new pathogen, especially when healthcare workers are at clear risk for disease. Additionally, cutbacks over the last number of years to hospital infection control and community public health programs have left health care workers ill-equipped to optimally manage new and/or unusual outbreak situations. The province plans to conduct a review of the SARS outbreak in Ontario. A full, open 
and frank evaluation of how this epidemic was managed, taking advantage of impartial consultants, is encouraged. It will hopefully provide guidelines for future responses and, importantly, for the best methods to communicate balanced information to the general public.

Placing SARS into perspective is key and Schabas (21) recently provided a unique commentary on the topic. Acknowledging the seriousness of SARS, he noted that there would have been 100 influenza related deaths in the eight week period during which SARS was present in Ontario, and at least 200 deaths from motor vehicle accidents. Influenza has attack rates in the community of up to $40 \%$; if SARS were anything like the influenza epidemic of 1918 the number of deaths in Canada would already be in the tens of thousands, and in the millions worldwide. The monthly death toll in 1918 was over 10,000 per month and 700 per day at its peak in Philadelphia (25). The case fatality rate in adults was as high as $15 \%$ and approached $50 \%$ in young adults during the peak of the epidemic (25). In Western Samoa in 1918, 20\% of the entire population died within a two month time frame (25). Clearly any comparison of SARS to the 1918 influenza pandemic was in appropriate. The evidence to date suggests that SARS is not as

\section{REFERENCES}

1. WHO. Severe Acute Respiratory Syndrome (SARS) - Multi-country outbreak. < http://www.who.int/csr/don/2003_03_15/en/> (Version current at May 14, 2003).

2. Update: Outbreak of severe acute respiratory syndrome - Worldwide, 2003. MMWR Morb Mort Wkly Rep 2003;52:241-8.

3. Tsang KW, Ho PL, Ooi GC, et al. A cluster of cases of severe respiratory syndrome in Hong Kong. New Engl J Med 2003.

<http://content.nejm.org/cgi/reprint/NEJMoa030666v3.pdf> (Version current at May 14, 2003).

4. WHO. WHO issues a global alert about cases of atypical pneumonia. <http://www.who.int/csr/sarsarchive/2003_03_12/en/> (Version current at May 14, 2003).

5. WHO. Viet Nam removed from list of affected countries, more than 5000 probable cases worldwide. <http://www.who.int/csr/sarsarchive 12003_04_28/en/> (Version current at May 14, 2003).

6. Gerderding JL. Faster...but fast enough? Responding to the epidemic of severe acute respiratory syndrome. New Engl J Med 2003. $<$ http://content.nejm.org/cgi/reprint/NEJMe030067v1.pdf> (Version current at May 14, 2003).

7. SM Potanen, DE Low, B Henry, et al. Identification of severe acute respiratory syndrome in Canada. N Engl J Med 2003. <http://content.nejm.org/cgi/reprint/NEJMoa030634v3.pdf> (Version current at May 14, 2003).

8. Peiris JSM, ST Lai, LL Poon, et al. Coronavirus as a possible cause of severe respiratory syndrome. Lancet 2003;361:1319-25.

9. N Lee, D Hui, A Wu, et al. A Major Outbreak of Severe Acute Respiratory Syndrome in Hong Kong N Engl J Med 2003. <http://content.nejm.org/cgi/reprint/NEJMoa030685v2.pdf> (Version current at May 14, 2003).

10. Peiris JS, Chu CM, Cheng VCC, et al. Prospective study of the clinical progression and viral load of SARS associated coronavirus pneumonia in a community outbreak. <http://www.who.int/csr/sars

/prospectivestudy/en/index.html > (Version current at May 14, 2003).

11. Heymann, DL. Update 27 - One month into the global SARS outbreak: Status of the outbreak. <http://www.who.int/csr/sarsarchive /2003_04_11/en/> (Version current at May 14, 2003).

12. WHO. First data on stability and resistance of SARS coronavirus compiled by members of the laboratory network.

<http://www.who.int/csr/sars/survival_2003_05_04/en/index.html> (Version current at May 14, 2003). contagious as influenza, and transmission appears to have been contained with the use of rigorous infection control practices. Nonetheless, it is a transmissible viral pneumomia which can cause significant illness in the majority of adults whom it infects, and unfortunately is a cause of mortality in those with advanced age or underlying illness, and in a small percentage of previously healthy adults.

SARS is likely here to stay and will present a new challenge for health care workers, particularly in the hospital setting. Cases in the future are anticipated, either from transmission from individuals with minor symptoms or from importation of new cases. A solid and rational plan for the future is needed and health officials from across the country will have to grapple with the new reality. It will be a formidable but not unrealistic task to provide rapid diagnostic tests and develop effective treatment. The greatest impact will be on how we care for patients presenting to physicians and nurses in the community and the hospitals with symptoms suggestive of a lower respiratory tract infection. Greater levels of infection control and, most importantly, greater levels of respect for the need for appropriate hygienic precautions will be required by all health care workers in the future.

13. Drosten C, Günther S, Preiser W, et al. Identification of a nove coronavirus in patients with severe acute respiratory syndrome. N Engl J Med 2003. <http://content.nejm.org/cgi/reprint/ NEJMoa030747v2.pdf > (Version current at May 14, 2003).

14. Ksiazek TG, Erdman D, Goldsmith CS. A novel coronavirus in patients with severe acute respiratory syndrome. N Engl J Med 2003. <http://content.nejm.org/cgi/reprint/NEJMoa030781v4.pdf> (Version current at May 14, 2003).

15. Health Canada. Severe acute respiratory syndrome (SARS) - for health professionals. <http://www.hc-sc.gc.ca/pphb-dgspsp/sars-sras/prof_e.html> (Version current at May 14, 2003).

16. Health Canada. Summary of severe acute respiratory syndrome: Canada and international. <http://www.hc-sc.gc.ca/pphb-dgspsp/sars-sras/euae/sars20030428_e.html> (Version current at May 14, 2003).

17. Ministry of Health and Long Term Care. Ministry of Health and LongTerm Care Ontario takes additional precautions in response to SARS <http://ogov.newswire.ca/ontario/GPOE/2003/03/29/c5549 .html?lmatch=\&lang=_e.html $>($ Version current at May 14, 2003).

18. Ministry of Health and Long Term Care. Ministry of Health and LongTerm Care Ontario extends hospital restrictions provincewide to contain SARS. <http://ogov.newswire.ca/ontario/GPOE/ 2003/03/31/c6006.html?lmatch=\&lang=_e.html> (Version current at May 14, 2003).

19. SARS in the balance. The Globe and Mail (Toronto) 2003 Apr 16;Sect A:16. (Edit)

20. SARS fight calls for strong action. Toronto Star 2003 Apr 17;Sect A:28. (Edit)

21. Schabas R. SARS: Prudence, not panic. Can Med Assoc J 2003. <http://www.cma.ca/cmaj/early_releases/sars-schabas-la.pdf>. (Version current at May 14, 2003).

22. Brean J. The WHO is saying they blew it. National Post 2003 April 30;Sect A:1.

23. Brean J. Outbreak predicted to cost city $\$ 1$ billion. National Post 2003 May 3;Sect A:6.

24. Blackwell T. SARS stopped itself, health expert says. National Post 2003 May 3;Sect A:7.

25. Steinhoff M. Epidemiology and prevention of influenza. In: Nelson K, Williams C, Graham N, eds. Infectious Disease Epidemiology - Theory and Practice. Gaithersburg: Aspen Publishers, 2001:477-94. 


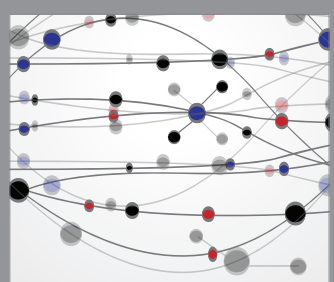

The Scientific World Journal
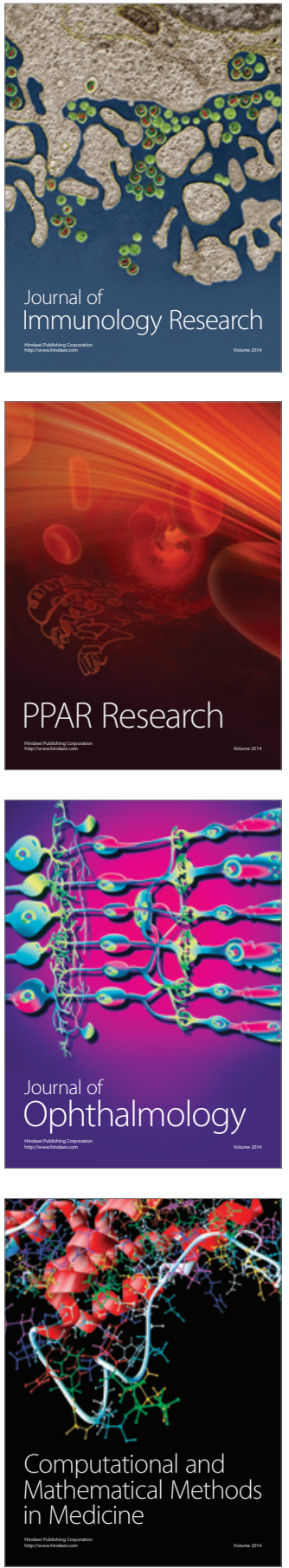

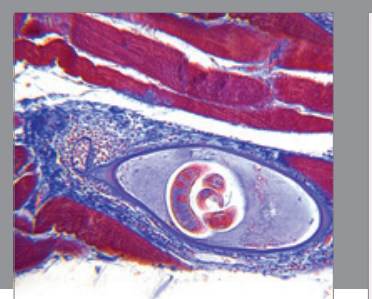

Gastroenterology Research and Practice

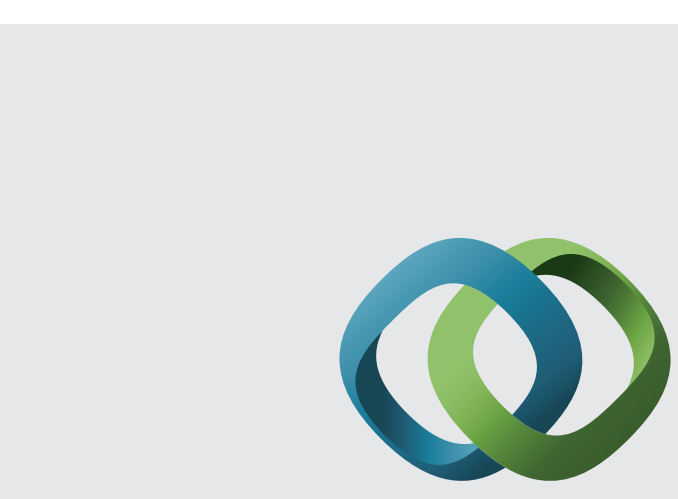

\section{Hindawi}

Submit your manuscripts at

http://www.hindawi.com
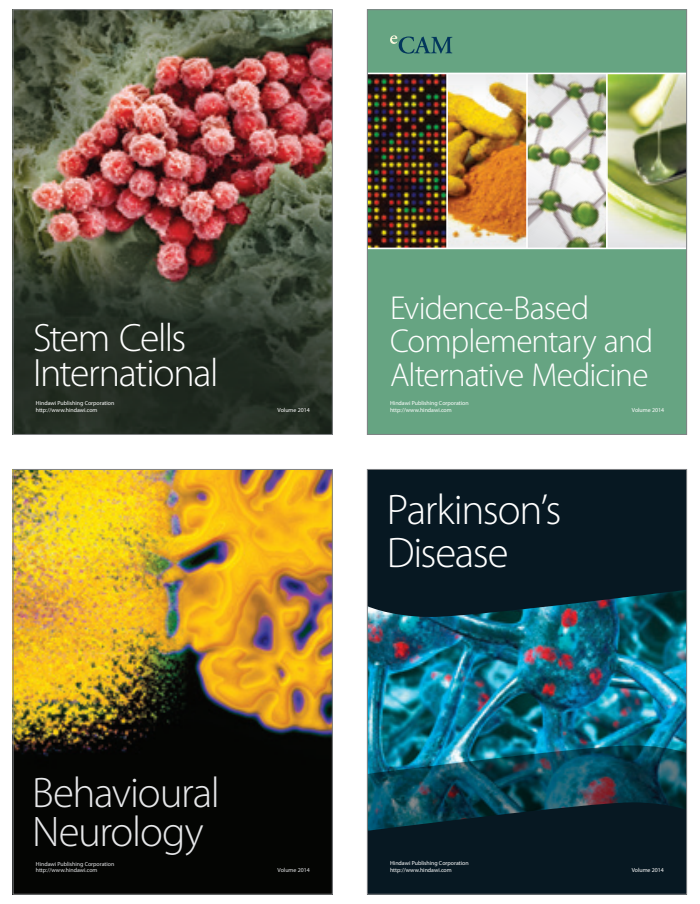
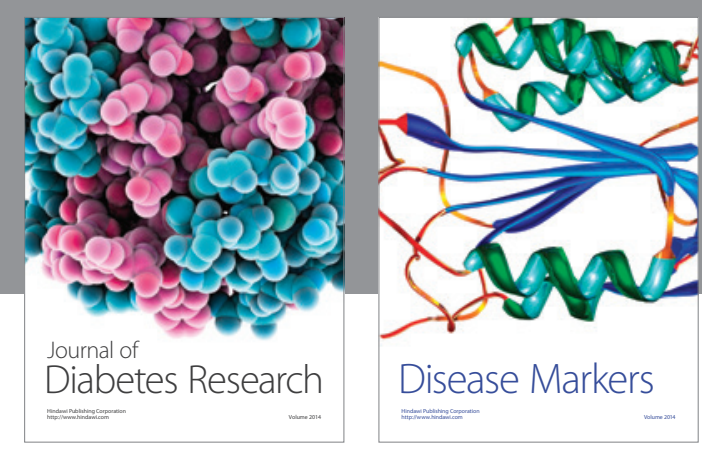

Disease Markers
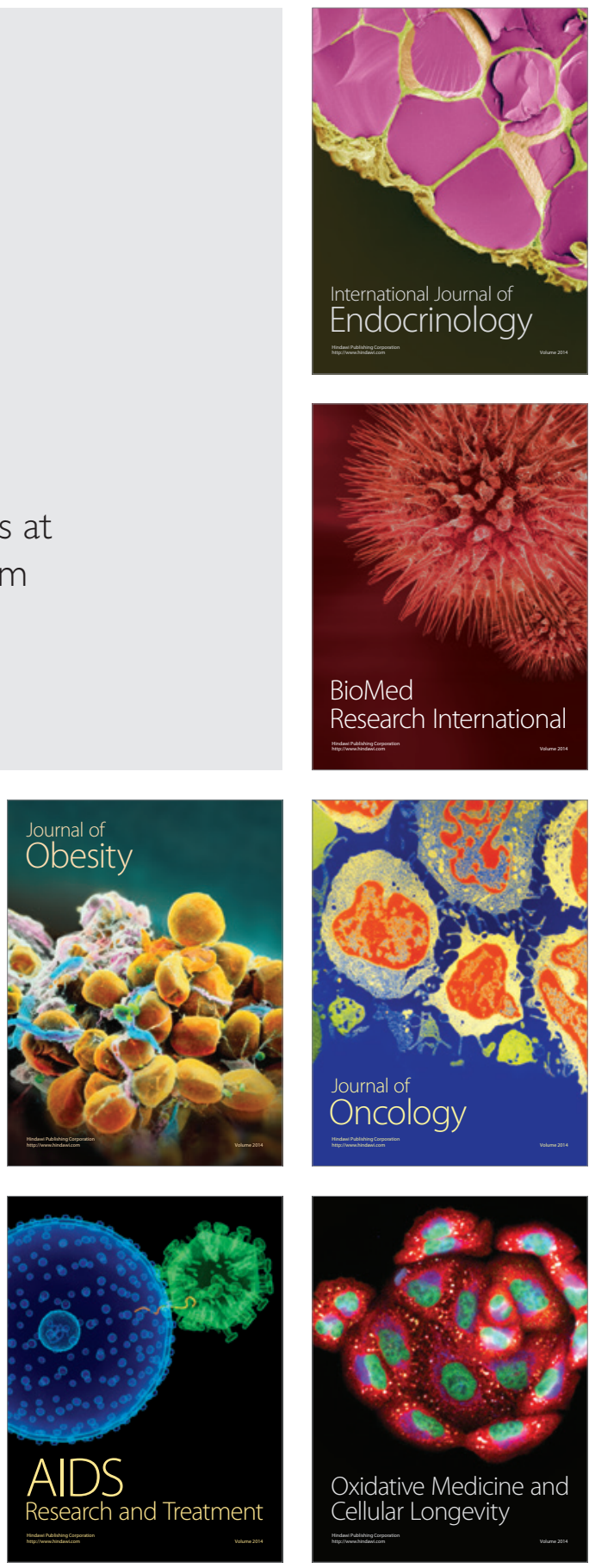